incomplete, but usually a more striking feature is its slowness and the effort necessary to execute it. This conjugate paresis may be associated with erroneous projection towards the homolateral side. It diminishes gradually, but the difficulty in movement to this side, in comparison with deviation in the opposite direction, frequently persists for weeks. The vertical movements of the eyes and convergence are never similarly affected.

Occasionally the position known as "skew-deviation" is observed in patients with acute cerebellar lesions, that is the homolateral eye is directed downwards and inwards and the other upwards and outwards. This lack of parallelism in the optic axes disappears on fixation, when this can be obtained, and consequently diplopia does not result. It is produced only by extensive destruction of the cerebellum, and has not, in my opinion, any localizing value.

\title{
OCULAR PALSIES*
}

\author{
BY \\ Leslie Paton \\ LONDON.
}

THE subject of ocular palsies is one of great complexity, and in its consideration the relationship of the oculomotor mechanism to many different parts of the central nervous system has to be taken into account. If we take only one disease, syphilis, and consider the different ways in which it can produce an ocular palsy, it will enable us to realize dimly the complexity of the subject. Syphilis may affect directly any part of the oculomotor apparatus, cortical, supranuclear, nuclear, nerve roots, nerve trunks in their intra-cranial course, in the cavernous sinus, or in the orbit, or it may afrect the muscles themselves. A gumma may develop at any point. A syphilitic meningitis may affect the nerves. Syphilis sets up disease of the vessels and we may get haemorrhages affecting the nuclei or nerve roots, or a syphilitic arteritis in the internal carotid may press on nerve trunks in the wall of the cavernous sinus, or an endarteritis may affect the vessels supplying the crura, the mid brain or the pons, and give rise to areas of softening; or syphilis may give rise to tabes or general paralysis, and to all the variety of ocular disturbances arising in these diseases. Yet it is doubtful if more than 40 per cent. of cases of ophthalmoplegia are due to syphilis, directly or indirectly.

*Introductory paper read before the Sections of Neurology and Ophthalmology of the Royal Society of Medicine on March 10 and 11, 1921. 


\section{Classification of Oculomotor Paralyses}

Ocular palsies may be classified in three main groups :-

.I. Paralyses of central or cerebral origin, comprising three sub-groups :-

(1) Supranuclear lesions.

(a) Cortical.

(b) Subcortical.

(2) Internuclear lesions.

(3) Nuclear and nerve root lesions.

II. Paralyses of extra-cerebral origin, i.e., of nerve trunks, again comprising two sub-groups :-

(1) Intracranial.

(2) Intraorbital.

III. Paralyses of muscular origin.

It is important in this connection to remember that disturbances of ocular movements may result from lesions affecting the afferent nerves as well as from those affecting efferent nerves, and also, that there are important afferent nerve fibres concerned in the control of ocular movements in the oculomotor nerves, in the optic nerves, in the vestibular nerves, and in the nerves from the muscles of the head and neck. ${ }^{1}$

It is to the sub-group (3) in Group I-Paralyses of nuclear and nerve root origin-that Mauthner applies the term "Ophthalmoplegia" in its more limited sense, and it is more especially with this and the internuclear group that I deal in this paper.

\section{PART I.-ANATOMICAL}

The nuclei of the oculomotor nerves lie in the grey matter in the floor of the aqueduct of Sylvius, reaching forwards into the floor of the third ventricle and backwards into the floor of the fourth ventricle. The nucleus of the third nerve passes without a definite interval into the nucleus of the fourth, but the sixth nucleus is distinctly separated from the fourth, and lies in the grey matter in the floor of the fourth ventricle, separated from the ependyma by the curving fibres of the seventh nerve root.

The dorsal or posterior longitudinal bundle coming up from below forms connections with all these nuclei. It runs ventral to and to the inner side of the sixth nerve and ventral to and slightly to the outer side of the fourth and third, and then continues on round the red nucleus. It contains both ascending and descending fibres.

Dorsal to the grey matter in this neighbourhood lies another longitudinal bundle of fibres, the bundle of Schütz.

.The third nucleus is composed of two main lateral groups of large cells (about $40 \mu$. in diameter) forming crescents with the concavity outwards, rounded dorsally and fining off ventrally. 
Between the two anterior horns of these crescents, and lying in the more dorsal area, are two groups of smaller cells, almost touching in the middle line. Like the lateral groups, they are broader dorsally and thinner ventrally, and comma shaped anteroposteriorly: these are known as "Edinger-Westphal nuclei." Ventral, and slightly posterior to those, lying exactly in the middle line, is a single spindle-shaped group of large cells-the nucleus of Perlia. A few scattered lateral cells lie outside and amongst the fibres of the posterior longitudinal bundle.

Lying above and to the outer side of the anterior end of the lateral mass, there is another group of cells to which an oculomotor function has been ascribed by $\mathrm{Knies}^{2}$ - the nucleus of Darkschewitsch.

Numerous commissural fibres pass from the cell groups on the two sides of the mid line, but as we reach the region of the fourth nucleus, these disappear. Though there is no definite separation between the third and the fourth nuclei, there is a space where cells are less numerous, and the region of the fourth is indicated by the disappearance of the crossing fibres.

The researches of Bernheimer ${ }^{3}$, Westphal and others seem to indicate that the small-celled mesial nuclei of Edinger and Westphal are concerned in the innervation of the sphincter pupillae, and that the large-celled single median nucleus supplies the ciliary muscles. As the description in most text-books is based on Bernheimer's work, it has come to be accepted in a more dogmatic fashion than is desirable, and it has been strenuously combated by $\mathrm{Bach}^{4}$, Marina and others. Bach found no signs of degenerative changes in the Edinger-Westphal nucleus after exenteration of the orbit in apes and exenteration of the eye in cats and dogs, and Marina's work on the same lines was confirmatory of Bach's. Tsuchida ${ }^{5}$, working under von Monakow, came to the conclusion that there was no definite evidence to show that this nucleus was connected with oculomotor innervation. Brouwer ${ }^{6}$ considers that too much stress has been laid on the absence of the obvious degenerative changes in the cells of this nucleus in cases of Argyll Robertson pupil, and in other cases where an ophthalmoplegia interna has co-existed with an ophthalmoplegia externa. He agrees with Westphal and Bernheimer in associating it with the innervation of the iris and adopts the name suggested by Jacobsohn" - " Nucleus sympathicus nervi oculo motorii."

Magitot $^{8}$, in a recent book on the Iris (Paris, 1921), states that, in his opinion, none of these groups of cells in the third nerve nucleus are concerned in the innervation of the sphincter, since they are not yet developed in the human embryo at a time when the light reflex already exists. Tsuchida has shown that all the accessory nuclei of the third, Edinger-Westphal, Darkschewitsch, 
Bechterew, etc., only make their appearance in the seventh month of intra-uterine life, and Magitot has seen the light reflex manifest in premature infants at the beginning of the sixth month.

In Magitot's opinion, the control of the sphincter is by a continuation up into the bulb of the same column of cells which gives rise to the dilator fibres in the cord, the intermedio-lateral tract, and that the whole control of the iris is a function of the sympathetic system, and so can be brought into line with Gaskell's theories.

The literature on this subject is enormous, but from the little I have read of it I can only give the Scots verdict of "Not Proven."

With regard to the group of cells described by Darkschewitsch, a more definite assertion can be made that they are not connected with the oculomotor nuclei, but are definitely connected with the fibres which compose the posterior commissure at the back of the third ventricle. According to Bernheimer, ${ }^{3}$ they link up the posterior longitudinal bundle with the posterior commissural fibres.

There is no anatomical separation of the large-celled lateral group, and the evidence as to the place of origin of the nerve fibres of the different muscles in different parts is very contradictory. I have copied, for your edification, a diagram from Brouwer's ${ }^{6}$ paper already referred to, and it serves to show how various are the views of different workers.

If only on a priori grounds, we must assume that the internal recti nuclei lie in that part of the lateral group where the crossing fibres are numerous, and similarly, the inferior oblique and inferior rectus nuclei probably lie where there are crossing fibres. Now, these are most numerous in the posterior half. That would then indicate that the anterior ends of the lateral crescents of large cells are concerned in the innervation of the levator palpebrae superioris and the superior rectus. Then when the middle parts of the crescents come closer and into relationship with the smallcelled paired nuclei, and the large median nucleus, the rectus internus is represented, and behind that, where the crossing fibres are numerous, the inferior rectus and the inferior oblique.

When, however, we think how intimately every ocular muscle is concerned in every movement of the eye, and how there is never a movement which does not imply some contraction of one set and some relaxation of another set, we may be forced to the conclusion that each muscle must be more or less represented all through the oculomotor nucleus, and that at least a number of the cells present, and especially the cells of the central nucleus, are in the nature of intercalary cells, linking up the movements of different muscles, and the movements of the two eyes. Now if there are, as I think, intercalary cells present, they would belong to a higher level neuron, and consequently would not suffer degenerative 


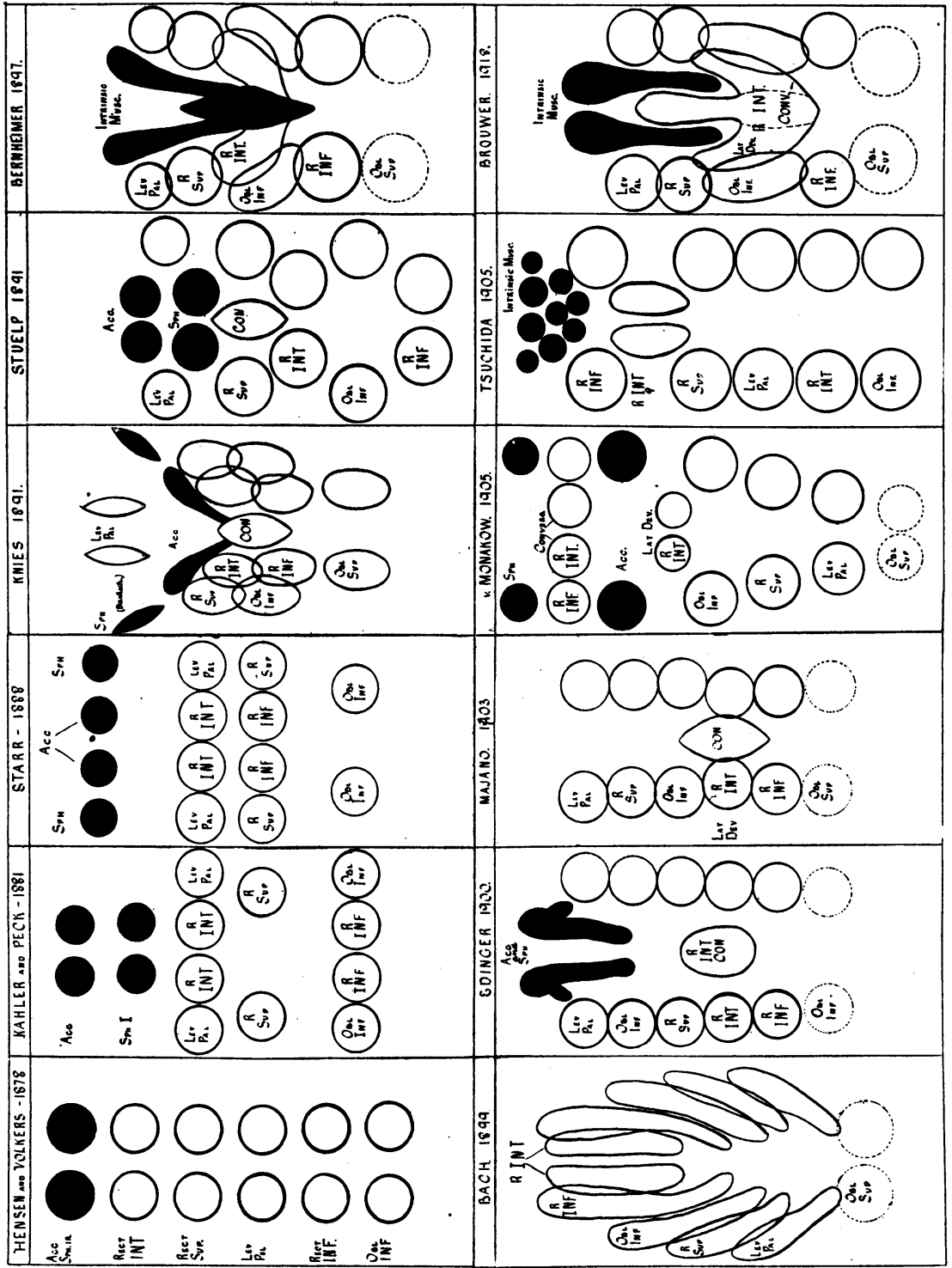

From Brouwer Zeitschrift fur die ges. Neur. und Psych. Vol. XL, 1918. 
changes so early as the cells connected with the direct motor neuron, when the nerve fibre originating from it is affected.

The fibres arising from the fourth nucleus, unlike those arising from the posterior part of the third nerve, do not cross before emergence from the brain substance, but pass first obliquely downwards, and then turn dorsalwards, and emerging from the brain substance, cross in the velum medullare in the anterior part of the roof of the fourth ventricle.

The nerve fibres from the sixth nucleus do not cross, but pass ventrally to supply the external rectus of the same side. Obersteiner has described fibres crossing the raphe between the - two sixth nuclei, but it is by no means certain that these fibres are related to the sixth nuclei, since at this position, the dorsal longitudinal bundle lies between the cell groups and the middle line, and the fibres crossing the raphe at this level may be from the dorsal longitudinal bundle, or from Deiter's nucleus, crossing to enter the dorsal longitudinal bundle of the opposite side.

The three nuclei are all intimately linked up with one another, and with lower centres, by bundles of longitudinal fibres, and so important are these linking fibres that Lhermitte $^{9}$ has suggested the use of the term "internuclear paralysis" to distinguish the important forms of paralyses that may occur from lesions in the course of these fibres, and differentiate them from supranuclear, nuclear, and infranuclear paralyses. Of the connections of the dorsal longitudinal bundle of Schütz which lies dorsal to the oculomotor nuclei in the ependymal grey matter surrounding the aqueduct of Sylvius, I must confess my ignorance. Schütz supposed it to be a connecting link between the oculomotor nuclei, but it has been traced into a nucleus, the dorsal tegmental nucleus of Gudden, in front of the oculomotor area, and backwards, still in the ependymal tissue, in the floor of the fourth ventricle, to the pons and medulla. It is presumed to be a primitive tract linking up the olfactory system with the oculomotor nuclei and lower motor nuclei. ${ }^{* 10}$ and 11

The most important bundle of internuncial fibres linking up the oculomotor nuclei is the posterior longitudinal bundle. This may be described as a composite bundle composed of axones arising in different groups of cells. It contains both ascending and descending fibres. It can be traced right down the cord in the anterior column, linking up with anterior horn cells, and anteriorly it can be traced forwards into the subthalamic region, and recently Fraser has traced it into the thalamus. Its anterior connections are somewhat obscure, but it receives fibres from the nucleus of Darkschewitsch, which brings it into relationship with the posterior

*Vide Addendum, Wherry's case, T.O.S., Vol. XI, p. 118. 


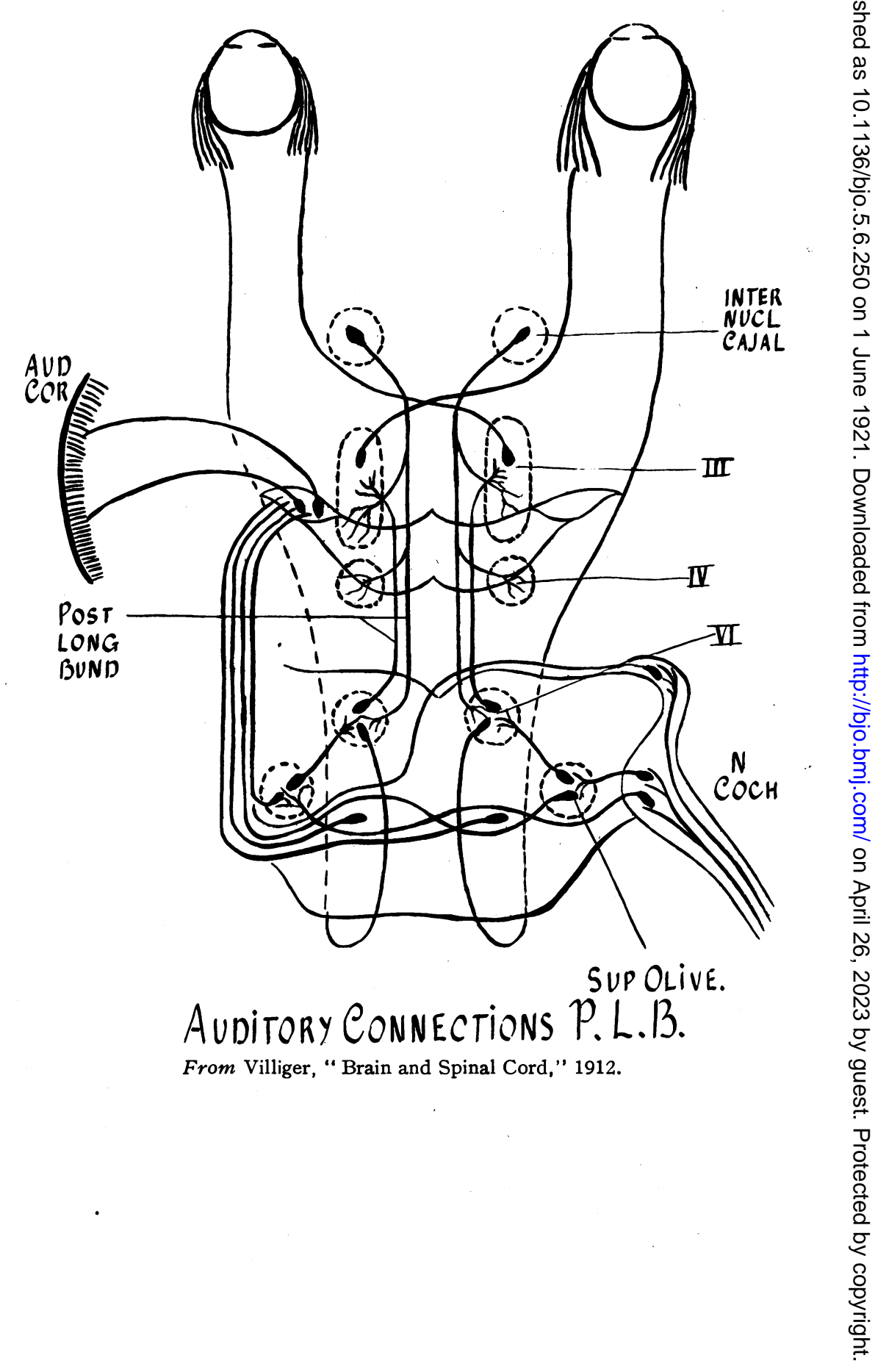


commissure. The ventral portion of the bundle is formed from fibres arising in the anterior corpora quadrigemina which curve down, pass in front of the third nuclei, decussate and then turn downwards. This particular bundle of fibres was described by Held $^{12}$ in 1890 as the predorsal longitudinal bundle. The descending fibres of the posterior longitudinal bundle are largely derived from the nucleus of Cajal, 10 which lies mesial to the anterior end of the third nucleus. Passing further back, we find it connecting up by numerous fibres with the third, the fourth, and the-sixth nucleus. On the level of the sixth nucleus is found its most important nucleus of "origin-Deiter's nucleus (Van Gehuchten). ${ }^{28}$ Axones arising from the cells of Deiter's nucleus curve in towards the raphe. Some cross, and some remain on the same side. Both crossed and uncrossed branch into ascending and descending fibres, and it is these ascending fibres from Deiter's nucleus that form the communicating link between the vestibular and the oculomotor nuclei. The posterior longitudinal bundle also receives.numerous fibres from cells in the formatio reticularis. It is said also to link up with the sensory nucleus of the fifth. A well-marked bundle of fibres sweeps up from the superior olive towards the nucleus of the sixth. These fibres are said to end in the sixth nucleus, but some probably pass up into the posterior longitudinal bundle. As the superior olive is connected by the trapezium with the auditory nuclei, this probably forms the path of communication between auditory sensations and the oculomotor nuclei. The posterior longitudinal bundle is continued down through the medulla to form part of the anterior column of the cord and thus links up with anterior horn cells.

The diagrams from Villiger's ${ }^{13}$ "Brain and Spinal Cord," 1912, pp. 182 and 183, illustrate some of these important connections I have attempted to describe.

The dorsal longitudinal bundle is of such great clinical importance that I have ventured in the classification of ocular palsies to put in a separate class of "inter-nuclear palsies." One of its functions is to bring the action of the external rectus of one eye into relationship with the internal rectus of the opposite eye. As is well known, a lesion in the sixth nucleus or its neighbourhood produces not only loss of outward movement of the eye on the affected side, but a defect in the action of the internal rectus of the other eye, only observable in conjugate lateral movement to the aftected side and not present in convergence. Duval and Laborde ${ }^{14}$ suggested that fibres originating in the sixth nucleus pass up the dorsal longitudimal bundle, enter the third nucleus and cross to the nucleus of the opposite side, and pass out with the third nerve to the right internal rectus. Neither von Gudden nor von Koelliker have 


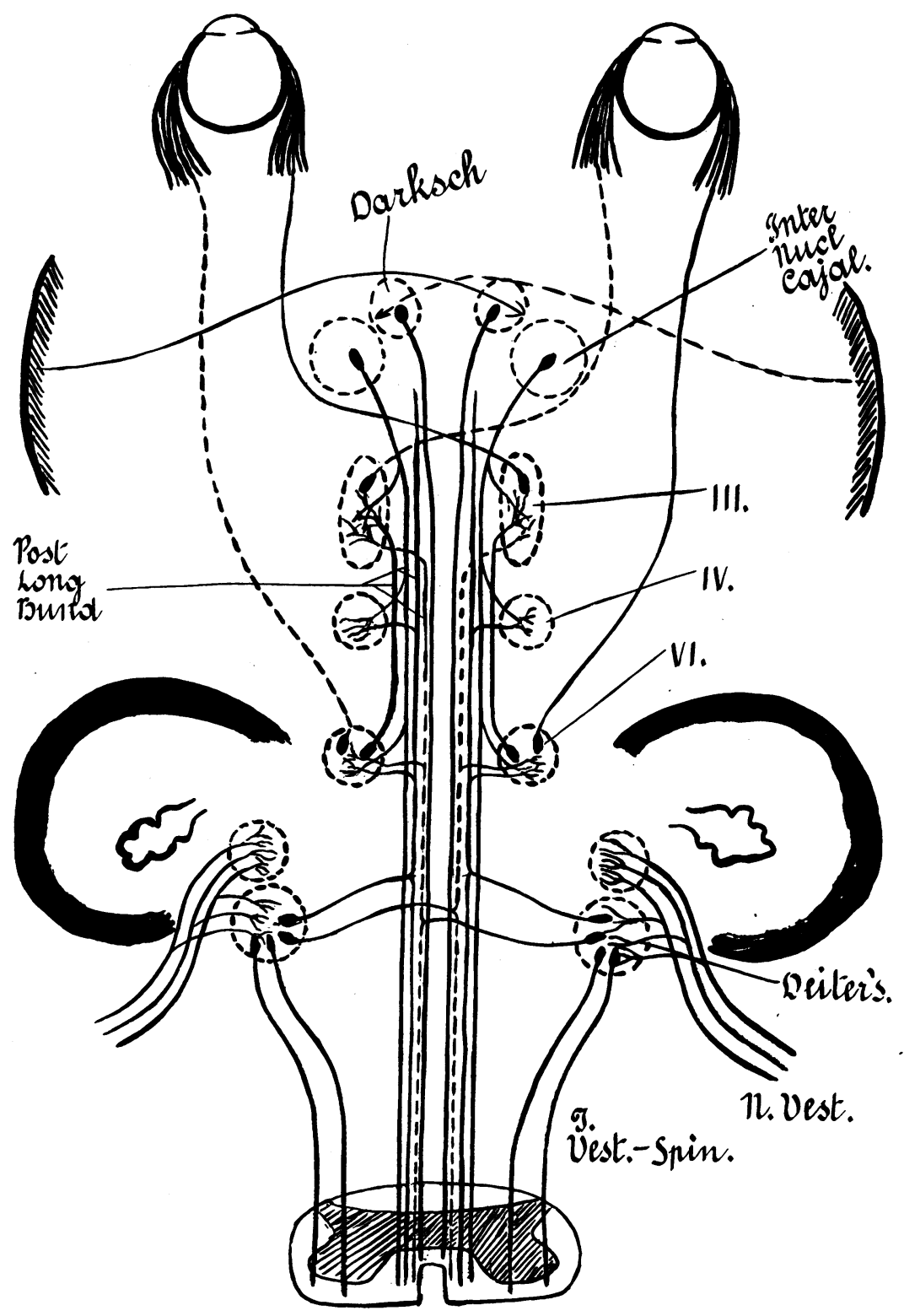

Vestibular Connections. P. L. $\mathcal{B}$.

From Villiger, " Brain and Spinal Cord," 1912 (modified). 
been able to find any proof of this assumption, and it seems more probable, from other associated ocular movements, that the internal recti are supplied partly by direct fibres from the nucleus of the same side, and partly by crossed fibres from the opposite nucleus. In which case, the longtitudinal bundle will serve as a link in the chain bringing the sixth nucleus of one side into communication with the cells of origin of the crossed fibres of the third, either directly or more probably through the interposition of intercalary cells.

It must not be forgotten, as Sherrington ${ }^{1}$ has shown, that every active contraction of the internal rectus implies an active relaxation of its antagonistic external, and these inhibitory impulses also may well be communicated along the posterior-longitudinal bundle.

\section{Vascular Supply}

The important part that vascular lesions play in the causation of oculomotor paralyses is well recognised. Many of the acute ophthalmoplegias occurring in infective or toxic diseases are the result of vascular changes set up in these diseases. But we also get more direct vascular lesions resulting from the bursting of miliary aneurisms in the smaller cerebral vessels, and haemorrhages from the smaller arteries in arterio-sclerosis, and in other forms of local or general arteritis. Furthermore, the oculomotor nuclei, nerve roots, or association fibres, may be involved in areas of cerebral softening, resulting from thrombosis, or the nerves in their intracranial course may be pressed on by aneurisms in the larger basal vessels, and the third, and to a less extent, the fourth nerves are liable to be affected by thickening of the internal carotid in the cavernous sinus.

In the first place, it is important to realise that the area of oculomotor nuclei is supplied by end arteries and that there is no collateral circulation. These end arteries come either directly from the basilar or from the posterior cerebral, very soon after its bifurcation. Clinically, there seems much evidence pointing to a separate supply for the anterior and posterior parts of the nucleus. The vessels run dorsally upwards on the inner side of the bifurcation of the crura. Leon d'Astros and Alezais ${ }^{15}$ sub-divide the supply into three lots of branches arising from one artery from the posterior cerebral, an anterior set passing horizontally forwards to the anterior end of the third nucleus; a middle set passing vertically; and a posterior set passing obliquely to the posterior end of the third and the fourth nucleus. Bernheimer ${ }^{3}$ claims to have traced a separate supply to the Edinger-Westphal nucleus from the dorso-lateral region of the crura, a branch from the vessel supplying the anterior corpus quadrigeminum. 


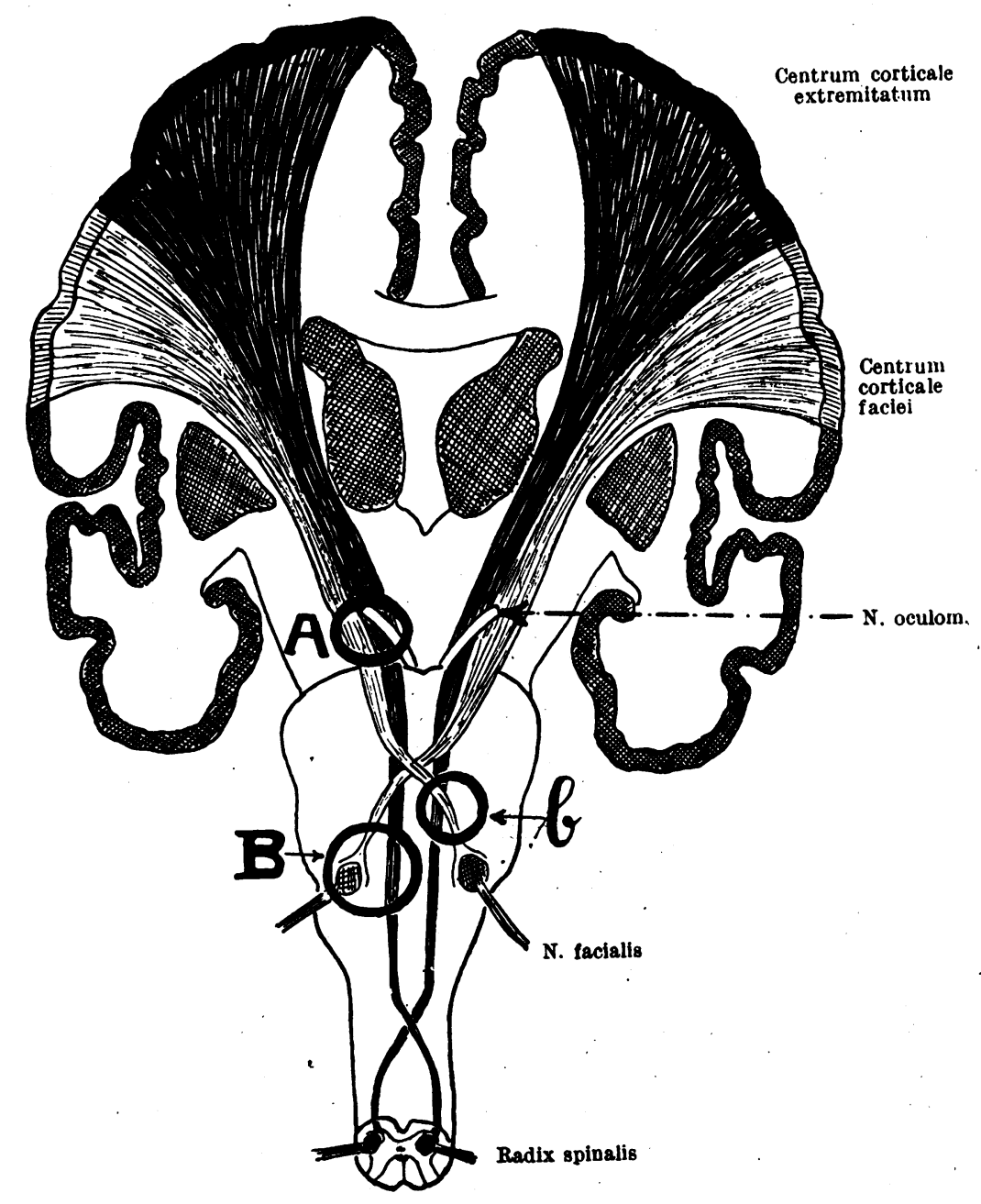

From Bing " Kompendium der topischen Gehirn und Rückenmarks Diagnostik," 2nd Edit., 1911. 
Very few cases of limited or partial affections of the oculomotor nuclei from vascular lesions have been examined pathologically, and in the few autopsies made, the interpretation has been confused by the fact that nerve roots, as well as cells, have been involved in the affected area.

In the great majority of cases of haemorrhage or softening affecting this region, the crura cerebri, the mid brain and the pons are the main sufferers. The resulting ophthalmoplegia is often more properly a nerve root lesion than a nuclear lesion. These form the typical crossed hemiplegias.

The interest of these crossed hemiplegias may be my excuse for digressing for a few moments from my main subject. I have cơpied a diagram from Bing ${ }^{16}$ to illustrate some of the principal forms. They may result from any form of lesion, vascular, tuberculous, gummatous, neoplastic or inflammatory, affecting the pons or the cerebral peduncles.

Commencing from above, we get the typical "Weber's syndrome," a complete paralysis of one third nerve, with a hemiplegia of the opposite side. This lesion must be at the posterior end of the crus or the anterior end of the pons, and the roots of the third are involved on their way out.

In "Benedict's syndrome," there is oculomotor paralysis on one side, with tremors and convulsive movements of the opposite arm, or opposite limbs.*

The lesion in this type lies deeper in the mid brain and the nucleus ruber has been found to be markedly affected in such cases and consequently, the root fibres of the third, as they run through it.

In "Foville's syndrome," the lesion is situated lower down. The nucleus of the sixth is affected, and in addition to paralysis of the external rectus on the same side, there is loss of the conjugate deviating action of the internal rectus of the eye on the opposite side with hemiplegia of the opposite side, so that the eyes are turned towards the side of the paralysed limbs. There is facial paralysis on the side of the paralysed external rectus.

In the "Millard-Gubler syndrome," there is complete paralysis of the sixth and seventh on one side, with crossed hemiplegia, but the movements of the opposite internal rectus are unaffected. In this case, the lesion is near the posterior end of the pons, and the sixth root is affected, but not the sixth nucleus.

-I have tried to simplify my account of these complex conditions by leaving out the intricacies of the fifth nerve roots, and their participation in these lesions.

*Vide Addendum T.O.S.. Lees, Vol. III, p. 278, p. 281. Taylor, Vol. XVIII, p. 381. Jessop, Vol. XXIX, p. 271. Batten, Vol. XXX, p. 116. 


\section{PART II.-CLINICAL}

In the first part of my paper I have attempted to define an area of the central nervous system within which disease is almost certain to set up some derangement of the oculomotor system, and before going further, I think it is necessary to point out that there can be no sharply defined limits between lesions affecting nuclei, i.e., cell groups, nerve roots, or association fibres, and this is specially the case where the lesion is primarily or secondarily of vascular origin. Mauthner ${ }^{17}$ defined an ophthalmoplegia as a condition in which either muscles of both eyes are affected, especially if they are supplied by different nerves, or if the movements of one eye only are affected, more than one nerve of supply must show evidence of affection. This especially includes cases where all the eye muscles are affected-complete ophthalmoplegia - and also where all the external muscles are affected, and the sphincters of the iris and the ciliary muscles escape-ophthalmoplegia externa. Uhthoff definitely excludes from his discussion of the ophthalmoplegias double external rectus palsies and double isolated ptosis, on the grounds that though they are often undoubtedly of nuclear origin, they can also be due to other causes. I think it is further desirable to limit the discussion by excluding cases of pure ophthalmoplegia interna.

\section{Classification of Ophthalmoplegias}

\section{Acute and sub-acute Ophthalmoplegias.}

(A) Poisons.

Alcohol.

Lead.

Botuilism.

(Carbon monoxide; nicotine; snake poison; sulphuric acid.)

(B) Infective agents.

Diphtheria.

Influenza.

Lethargic encephalitis.

Syphilis.

Tubercle.

(Measles, typhus, chicken-pox, septicaemia, chills.)

(C) Trauma.

(D) No etiological factor.

II. Chronic (Progressive) Ophthalmoplegias.

(A) An isolated lesion.

(B) Tabes and General Paralysis.

(C) Disseminated Sclerosis.

Posterolateral sclerosis (sub-acute combined.)

Syringomyelia. Paralysis Agitans. 
(D) Bulbar Palsies. Progressive muscular atrophy. Myasthenia Gravis.

(E) Graves' Disease.

(F) Diabetes.

III. Congenital Ophthalmoplegias of nuclear origin.

IV. Unilateral Ophthalmoplegia.

V. Recurrent and alternating Ophthalmoplegia of nuclear origin.

\section{Acute Toxic Ophthalmoplegia}

Of the toxic forms of acute ophthalmoplegia, that due to alcoholic poisoning may be taken as the type. This was first described by Wernicke $e^{18}$ in 1881 , under the name of acute haemorrhagic polioencephalitis superior. In its most typical manifestation, it shows a rapidly developing ophthalmoplegia, sometimes affecting the pupils and sometimes accompanied by ptosis. The general condition renders it difficult to examine accommodation. The onset is accompanied often by somnolence, or there may be acute delirium. There is severe headache and giddiness. Bulbar nuclei become implicated and speech may be affected. The gait may become ataxic. Knee jerks may be lost, and other deep reflexes be affected, weakness may develop in all limbs, and death may follow in from ten to fourteen days. Not all the cases, however, end fatally, and in some which do so end, death does not take plàce for some time.

Autopsy shows numerous punctiform haemorrhages in the grey matter in the walls of the third ventricle, below the aqueduct of Sylvius and in the floor of the fourth ventricle. The vessels show fatty and sclerotic degeneration and cellular infiltration in their sheaths. The nerve stems at their exit from the brain are usually found to be healthy.

In lead poisoning, the majority of cases of oculomotor disturbance are probably due to a neuritis. In some cases, however, there is evidence of a nuclear origin, but these do not show the numerous other severe and acute cerebral complications found in alcoholism.

The clinical picture produced in botulism also differs in many respects from the Wernicke type. In practically every case; both pupils and ciliary muscles are paralysed, and in more than 50 per cent. of the cases, there is more or less pronounced double ptosis. The other ocular muscles may be affected in a varying degree. The general symptoms of a food poisoning usually precede the onset of the ocular symptoms, and point to the diagnosis. Experimentally, von Emengen, Marinesco and others have shown that degenerative changes take place in the grey matter in the region of the oculomotor nuclei. 


\section{Acute Infective Ophthalmoplegia}

I think I may be excused if, at the present time, I take lethargic encephalitis as an example of infective ophthalmoplegias. In its most typical manisfestations, the disease begins with a disturbance of oculomotor functions. Accommodation is almost invariably affected, the pupil very frequently, and in certain cases, a typical Argyll Robertson pupil has been described. The other ocular movements may be affected in such various ways as to suggest that the lesions may be nuclear, infranuclear, or supranuclear.

The marked somnolence which occurs in the disease is, as I have already mentioned, met with also in the alcoholic type of Wernicke, and as Mauthner showed many years ago, is a characteristic of various lesions affecting the region of the posterior end of the third ventricle. It is met with not infrequently in pituitary tumours, and Salmon has suggested that in these cases, it is due to disordered pituitary secretions. Marie and Trétiakoff have demonstrated, however, the integrity of the hypophysis in some cases of encephalitis where somnolence was a marked feature.

It is of interest to note how the onset of normal physiological sleep may be accompanied by signs of loss of activity of various ocular muscles. Many of you in reading may have noted how the print of the book may seem to diminish in size, or the objects in a room look as if seen through the wrong end of a telescope, a micropsia due to the increased effort necessary to maintain a failing accommodation. The increase in size of the pupils is common knowledge, and also the tendency of the words to blur and run into one another, owing to failing convergence power. Later comes on the ptosis of sleep, and with it, the unconsciousness. There seems to be little doubt that pathological somnolence may arise in the same way from disturbances in the neighbourhood of the third nuclei.

It is not within my capacity to discuss the symptoms resulting from the spread of the changes in encephalitis.lethargica into other parts of the basal grey matter, into the cortex, and even into the medulla and spinal cord.

Macroscopically, the grey matter in the mid brain is seen to be studded with small haemorrhages, and there seems little doubt that the favourite site of this affection is in the grey matter in the region of the aqueduct of Sylvius, and however widespread the lesions may be, they are often at their maximum in this neighbourhood. (Locus Niger. Pierre Marie and Trétiakoff.)

Microscopically, the lesions may be seen to be of three kinds :(1) A dense perivascular infiltration into the Virchow-Robin space. The cells composing this infiltrate are mononuclear lymphocytes, plasma cells of Unna, polyblasts and polynuclear neutrophils. Many 
vessels also show this space filled with red corpuscles, either as the result of rupture, or, according to Economo, from diapedesis, and according to Economo, the extravasation of red corpuscles is restricted to grey inatter; and does not take place where the vessels enter white matter. There is little doubt, however, that this is too narrow a view. The condition in many cases, as von Monakow has shown, may lead to more or less extensive thrombosis, not necessarily restricted to intracerebral veins, and this thrombosis itself may be the cause of some of the haemorrhages.

(2) The second type of lesion found is in the form of inflammatory nodules in the tissues away from the vessels, the cells in these being very similar in type to those found in the perivascular lesions.

(3) The third type of change is a phagocytosis of nerve cells, a condition called "neuronophagia."

It is quite obvious from lesions so extensive and so profound as are to be found in this disease that, though the site of election of the disease may be the nuclei, the commissural fibres and the nerve roots cannot escape being affected, and from the mode in which it spreads, we are justified in expecting to find supranuclear and infranuclear lesions, in addition to the more typical nuclear lesions.

As to the causative organism, the evidence at present seems to point to its being a filtrable organism described by Hervier and Levaditi, rather than the gram-positive non-filtering organism described earlier by Wiesner.*

Of other causes of acute infective polioencephalitis, influenza is probably the most important. Cases have been recorded showing the most varied extent of involvement of the extrinsic eye muscles. The pupils are sometimes affected and more frequently accommodation. While there is undoubted evidence that influenza can set up nuclear lesion, it may also at times cause ocular palsies from basal affections, or from a peri-neuritis.

The evidence as to the nature and site of the lesion causing oculomotor paralyses in diphtheria is very contradictory. According to Babinski, Enriques and Hallion, Muravieff and others, there is a primary affection of nuclei, and this is sometimes associated with a similar affection of anterior horn cells with secondary degenerative changes in the peripheral nerves.

Bielschowsky, Sidney Martin and others regard the nerve change as the primary one, a parenchymatous neuritis, and look on the changes in the nuclei and anterior horn cells as secondary. In the majority of diphtheria cases where there is an ocular palsy, it is only accommodation that is affected, and when, as is very frequently the case, the soft palate is also paralysed, the diagnosis of a diphtheritic

\footnotetext{
* Cases of Lethargic Encephalitis, vide Addendum, T.O.S., Vol. XXXXVII, Taylor,
} p. 168. Batten, p. 172 . 
cause for the condition is much strengthened. Personally, the only extrinsic eye muscles I have ever seen affected after diphtheria are the external recti, and they are said to be affected in about 10 per cent. of cases showing ocular palsies. It is only very rarely that other eye muscles are affected.

In some rare cases, injuries, especially blows on the head without any evidence of basal fracture, have produced ophthalmoplegias of nuclear origin.

There remains a very definite percentage of cases of acute or sub-acute ophthalmoplegia in which no definite etiological factor is discoverable. In Uhthoff's statistics, 33 per cent. of the cases fell into this category. At present, many of these would be, and are, classified as cases of lethargic encephalitis, but in course of time, a better sense of proportion will supervene, and when it ceases to be the "nine days wonder" of the Daily Press, we may again recognise that \not all cases of acute polioencephalitis are to be lumped together under that very convenient heading. The cases in which no etiological factor is discoverable may be classified in two groups:-(1) Those without other complications, and (2) those showing evidence of lesions in the lower part of the bulb. Probably many of the latter are cases of lethargic encephalitis. The first group is the larger, and a definite proportion of them are probably vascular in origin.

\section{The Chronic Progressive Ophthalmoplegias.}

In an earlier part of the paper, I have referred to the ophthalmoplegias which occur in association with vascular lesions affecting the crura cerebri and pons. A certain proportion of chronic ocular palsies is associated with evidences of patches of softening affecting these regions. But the diseases which bulk most largely in the causation of chronic progressive ophthalmoplegia are undoubtedly tabes and general paralysis.

(1) As an isolated lesion. Before dealing with these cases, however, it is desirable to point out that a form of chronic ocular palsy occurs without any sign of further affection of the central nervous system. It occurs mostly in comparatively young people, though in the case recorded by Lawford (Trans. Oph. Soc., Vol. VII., p. 260), the age at commencement was fifty, and one other case has been recorded commencing at fifty-three. In these cases, there may be complete ophthalmoplegia externa, with ptosis in both eyes, but neither pupils nor accommodation are affected. In this respect, Lawford's case was typical. This type occurs as a definite hereditary affection, vide papers by Beaumont and Bradburne in addendum.*

*T. O. S., Beaumont, Vol. XX, p. 258. Bradburne, Vol. XXXII, p. 142 
(2) In tabes and general paralysis. According to Uhthoff's ${ }^{19}$ statistics, about 20 per cent. of all cases of ocular palsies occur in association with tabes or general paralysis, and Wilbrand and Saenger ${ }^{20}$ found in 302 cases of tabes 22 cases of ophthalmoplegia $(7 \cdot 2$ per cent.). We must remember in these cases that we are dealing with cases the majority of which are syphilitic and that quite apart from tabes, syphilis can produce an ocular palsy in many different ways; but with all allowances, there is no doubt that tabes, and to a less extent, general paralysis, are very common causes of ophthalmoplegia. There seems to be little doubt that the primary changes take place in the cells of the nuclei, and that as time goes on, the whole neuron from the nucleus down to the muscle (and in the end, the muscle itself) becomes affected. The changes have been described in detail by Siemerling and Boedeker ${ }^{21}$. The cells are small and shrunken, or even completely degenerated, or they show vacuolation. The cell processes have disappeared and the nucleus and nucleolus are degenerate. There is definite glial overgrowth. The amount of nerve degeneration is proportional to the degree of cell degeneration shown. In the later stages, the degeneration reaches the muscle, and the same muscle may show some fibres completely atrophied, and others grossly hypertrophied and a great increase of interstitial connective tissue.

The fleeting diplopias and ocular palsies of early tabes have probably quite another explanation, and should not, I think, be regarded as early stages of a nuclear degeneration. Sherrington ${ }^{1}$ has made the interesting suggestion that these may be caused by an affection of the afferent proprioceptive fibres, which have been shown to exist in the oculomotor nerves.

(3) In disseminated sclerosis, temporary diplopias and temporary disorders of associated ocular movements are comparatively frequent, while permanent progressive ophthalmoplegia is one of the rarer manifestations of the disease. Probably quite a number of the disorders of eye movements which do not result in diplopia and are of a fleeting character, are missed or forgotten, when the more classic symptoms of disseminated sclerosis become manifest. I have seen cases in which two or three attacks of temporary diplopia at intervals of some years have occurred before any more definite signs of the disease have been shown. The clinical signs point to an interference with nerve roots or commissural fibres, rather than a nuclear palsy, and this is in consonance with what is known of the pathology of the disease. Similarly in the rarer forms of permanent ophthalmoplegia occurring in disseminated sclerosis, the lesion is probably infranuclear and due to plaques occurring in the pons or crura.

(4) We next come to a very definite group of cases where ophthalmoplegia is combined with a bulbar palsy or a progressive muscular atrophy, or where all three are present in combination. 
According to Uhthoff, ${ }^{19}$ about 19 per cent of the cases of chronic progressive ophthalmoplegia fall into this group, and in about half of these, the combination is one of ocular and bulbar palsies.

Chronic ocular palsies have been recorded in Graves' Disease, and in diabetes, but in the latter disease, we probably have to do much more frequently with a peripheral neuritis than with a palsy of nuclear or root origin.

\section{Congenital Ophthalmoplegias}

Congenital defects of ocular movements form by themselves a subject which might occupy the whole of our time. They can be divided into three different clinical groups :-

(1) The defective ocular movement is an isolated and non-progressive phenomenon.

(2) The defect is hereditary, and may be accompanied by other defects of an hereditary nature.

(3) Other elements of the central nervous system may show analogous congenital defects.

Pathologically, any part of the oculomotor system may be affected, so that at the one end we may get a complete aplasia of the oculomotor nucleus and at the other end all sorts of peculiarities in the development of the external musculature of the bulb.

In conclusion, I must acknowledge my indebtedness to various neurological friends for aid in looking up references, and to Professor Uhthoff's excellent account in Vol. XI of Graefe-Saemisch "Handbuch der Gesamten Augenheilkunde," and Volumes-I and VIII of Wilbrand and Saenger's "Neurologie des Auges."

\section{REFERENCES IN PAPER}

1. Sherrington.-Brain, Vol. XIII.

de Kleijn.-Arch. Néerlandaise de Physiologie, Vol. II, p. 644, 1918.

2. Knies. - "De Beziehungen d. Sehorgans und seiner Erkrankungen." Wiesbaden: Bergmann, 1893.

3. Bernheimer.-"Das Wurzelgebiet des Oculomotorius." Wiesbaden: Bergmann, 1898.

Graefe-Saemisch " Handbuch d. ges. Augenheilkunde," 2nd Edit., 1900.

4. Bach. - v. Graefe's A rch. für Ophth., 1898, Zeitsch f. Nervenheilkunde, 1900.

5. Tsuchida. - "Ueber die Ursprungskerne der Augenbewegungen und über die mit' diesen in Beziehungstehenden Bahnen im Mittel-und-Zwischen-Hirn." Arb. aus dem Hirn-Anat. Inst. in Zurich, Part ii, 1906.

6. Brouwer.- "Klinisch-anatomische Untersuchung über den Oculomotorius Kern." Zeitschrift für die ges. Neurologie und.Psychiatrie, p. 152, Vol. XL, 1918.

7. Jacobsohn.-"Ueber die Kerne des Menschliches Hirnstammes." Neurol. Central, 1909.

8. Magitot. "L'Iris," Paris, 1921.

9. Lhermitte.-Arch. d'Ophtal., Jan., 1921.

10. Cajal._." Histologie du Système Nerveux," Paris, 1911, Vol. II, p. 193.

11. Tilney and Riley.- "The Form and Functions of the Central Nervous System." New York, 1921.

12. Held.-Neurol. Central, 1890.

13. Villiger. - "Brain and Spinal Cord," 1912, pp. 182 and 183. 
14. Duval and Laborde. - "De l'innervation des mouvements associés du globe oculaire."

15. Leon d'Ástros and Alezais.- "Les artères nourrières des noyaux du moteur oculaire commun et du pathétique." Soc. de Biol; 1892.

16. Bing.- " Kompendium der topischen Gehirn und Rückenmarks Diagnostik," 2nd Edit., 1911.

17. Mauthner.- "Die Lehre von den Augenmuskellähmungen,". "Vorträge aus dem Gesamt gebiete der Augenheilkunde," Vol. II, p. 293. Wiesbaden : Bergmann, 1889.

18. Wernicke.- "Lehrbuch der Gehirnkrankheiten," Vol. II, pp. 229 and 242.

19. Uhthoff. - Graefe-Saemisch " Handbuch der Gesamten Augenheil kunde," Vol. XI, Part ii, Div. 1 and 2, 1911 and 1915.

20. Wibrand and Saenger.- "Die Neurologie des Auges," Vol. I, 1900, and Vol. VIII, 1921.

21. Siemerling and Boedeker.-Arch. f. Psychiat, 1897, Vol. XXIX, pp. 420 and 716 .

22. Hensen and Volkers.-Arch. f. Ophthal., 1878, Vol. XXIV.

23. Kahler and Pick.-Prager Zeitsch f. Heilkunde, II, p. 301, $18 \dot{8} 1$.

24. Starr. - Journal of Nervous and Mental Diseases, 1888.

25. Stuelp.-Arch. f. Ophthal., Vol. XLI.

26. v. Monakow. - "Gehirnpathologie," 1905.

27. Marina.-Deutsch Zeitschr. f. Nervenheilkunde, 1899.

28. Van Gehuchten.- "Le Nevraxe," Vol. I, 1902.

29. Edinger.- "Ueber den Bau der Nervösen Centralorgane."

\section{ADDENDUM}

Cases and Papers in the Transactions of the Ophthalmological Society on Ophthalmoplegia.

Vol. I.

Gowers, p. 117. "Paralysis of upward movements with optic neuritis." Both eyes.

Jackson, p. 139. "Eye symptoms in locomotor ataxy."

Nettleship, p. 164. "Double isolated ophthalmoplegia externa." Youth, aged 18. Pupils and accommodation unaffected.

Sturge, p. 165 . "Two cases of simultaneous paralysis of both third nerves." First case undoubtedly due to haemorrhage. Second case, probably a haemorrhage occurring in association with some inflammatory or neoplastic.lesion.

Benson, p. 265. "Ocular paralysis after diphtheria." Accommodation and soft palate affected, also ptosis and paralysis of external recti.

Vol. III.

Lees, p. 278. " Paralysis of right third with cerebral symptoms" A case of right third nerve paralysis with marked tremor in left arm and leg. Probably lesion in mid brain. No note of facial weakness; $v$. Taylcr's case, Vol. XVIII and Batten's case, Vol. XXX.

Lees, p. 281. "Paralysis of left sixth with spasmodic contractions of right face." Vol. IV.

Eales, p. 300. "Complete paralysis of accommodation and convergence." A girl, aged 13. No other nervous system lesion. Pupils active to light.

Vol. V.

Sharkey, p. 384. " Locomotor ataxy with ophthalmoplegia externa and interna."

Jessop, p. 386. " Diphtheritic cycloplegia, with absence of knee jerks, etc." Loss of-accommodation. Pupils active. No extrinsic paralysis of eye muscles. Soft palate affected. Knee jerks absent. Visual fields affected. .

Vor. VII.

Coupland, p. 228. "Ophthalmoplegia dependent upon thrombosis of caverncus sinus."

Robinson and Hutchinson, p. 250. "Ophthalmoplegia, externa and interna." Disease of right cavernous sinus resulting in its obliteration. Syphilitic origin. A discussion of some other cases of syphilitic ophthalmoplegia both of central and peripheral origin.

Lawford, p. 260." "Double ophthalmoplegia externa without other symptoms." Referred to in paper: v. also Beaumont, Vol. XX, p. 238. 